\title{
PREVALENȚA DICROCELIOZEI LA OVINE ȘI CAPRINE LA FERMA PRIVATĂ DIN SATUL GRADIȘTE, RAIONUL CIMIȘLIA
}

\author{
Nafornița Nicolae \\ Universitatea Agrară de Stat dim Moldova, or. Chișinău, Republica Moldova \\ Institutul de Zoologie al Ministerului Educației, Culturii și Cercetării, Chișinău, R. Moldova \\ E-mail: nicolainafornita@gmail.com \\ https://doi.org/10.53937/9789975315975.54
}

Abstract: $A$ survey incorporating field and abattoir studies was carried out on the prevalence of Dicrocoelium lanceolatum in sheep and goats in the village Gradiste, district Cimislia, the R. Moldova. Coprological studies on these animals revealed that $71,9 \%$ of sheep and $87,7 \%$ of goats were positive for dicrocoeliosis, with a mean number of eggs per gram of faeces (EPG) of 277,7 for sheep and 261,8 for goats. The necropsy liver examination of slaughtered animals revealed that $94.1 \%$ of sheep and $75 \%$ of goats were infected with D. lanceolatum and they had mean fluke burdens of 247.2 (sheep) and 298.1 (goats). No significant differences in fluke burden, liver lesion score and EPG count were observed between sheep and goats. The seasonal distribution of dicrocoeliosis indicated a higher percentage of infection in autumn and winter as compared with spring and summer. The potential role of migratory sheep and goats in the epizootiology of dicrocoeliosis is discussed.

Key words: sheep, goats, Dicrocoelium lanceolatum.

\section{INTRODUCERE}

Invaziile cu helminți la ovine, reprezintă un factor major de stres, care induce la diminuarea producției animaliere de origine ovină în Republica Moldova. La moment, creșterea ovinelor la noi în țară, devine un segment important al zootehniei, tot mai mult practicat, mai cu seamă în zona de Sud și Centru [4, 6, 8].

Paralel, în zonele geografice menționate, predomină pășunile uscate, 
fapt ce favorizează debutul și răsndirea unor boli parazitare, inclusiv și al dicroceliozei. Situație similara se găsește și pe pășunile satului Gradiște, raionul Cimișlia, unde dicrocelioza la ovine, în general, debutează fără semne clinice evidente, chiar și în cazul infecțiilor severe, iar majoritatea pierderilor se datorează diminuării producției de lapte în perioada de lactație, sporul în greutate și confiscării ficatului la tăierea ovinelor la abator $[2,3,5,9]$.

\section{MATERIALE ȘI METODE}

Studiul privind prevalența invaziei cu Dicrocoelium lanceolatum a fost efectuat timp de 1 an, din primăvara anului 2017- primavara anului 2018, la ferma privată de ovine și caprine din satul Gradiște, raionul Cumișlia, situată în zona de Centru al Republicii Moldova.

Pentru acest studiu, sau colectat probe de mase fecale direct din rect, individual, pentru fiecare animal, în ambalaj de polietilenă, strict individualizat și transportat la laboratorul de Parazitologie și Helmintologie al UASM, Facultatea de Medicină Veterinară, catedra Clinici II. Probele sau colectat de la animalele cu semne de slabire, apetit diminuat, productivitate de lapte scăzută.

În laborator pentru indentificarea ouălor de dicrocelium sau utilizat metodele coproovoscopice: Darling, Fulleborn, metoda spălării succesive (sedimentare) și metoda de sedimentare-centrifugare.

A doua metodă folosită în cercetările noastre, a fost sacrificarea și colectarea ficatului de la animalele tăiate și examinat în laborator pentru indentificarea formelor parazitare. La examinarea organelor colectate am utilizat așa metode ca: inspecția, palparea, secționarea ficatului și metoda spălăturilor succesive al maceratului de organ parazitat [10].

Un moment important la examinarea ficatului colectat a fost utilizarea unui sistem arbitrar de punctaje al leziunilor hepatice (LLS), propus de Sanz F.et al. (1987) și atribuit fiecărui ficat la necropsie, după luarea în considerare a leziunilor brute cauzate de parazit la ficat pe o scară de la 1 la 4 puncte [1] (Tabelul 1). 
Tabelul 1.Punctajul leziunilor hepatice

\begin{tabular}{|l|l|}
\hline Leziunile macroscopice & $\begin{array}{l}\text { Punctaj } \\
\text { atribuit }\end{array}$ \\
\hline Ficat normal & 0 \\
\hline $\begin{array}{l}\text { Ficat ușor indurat cu câteva striuri albe; suprafața secționată ușor, aglomerată cu } \\
\text { încărcătură redusă de forme parazitare }\end{array}$ & 1 \\
\hline $\begin{array}{l}\text { Ficatul usor imbracat cu numeroase striuri albe; suprafața secționată cu semne de } \\
\text { congestie moderată, cu o încărcătură mică de paraziți }\end{array}$ & 2 \\
\hline $\begin{array}{l}\text { Ficatul moderat acoperit cu striuri albe și cu semne de cicatrizare ușoară; conduc- } \\
\text { tele biliare apar îngroșate la secționare cu exudat cataral în lumen și o încărcătură } \\
\text { moderată a paraziților }\end{array}$ & 3 \\
\hline $\begin{array}{l}\text { Ficatul este dur la palpație cu semne evidente de cicatrizare, canalele biliare dilatate } \\
\text { și îngroșate cu zone de fibrozare severă și o încărcătură parazitară mare. }\end{array}$ & 4 \\
\hline
\end{tabular}

În total sau colectat 250 probe de mase fecale, inclusive de la 185 de ovine și 65 - de la caprine, iar examinarea ficatului s-a efectuat la 25 animale, inclusiv de la 17 ovine și 8 caprine sacrificate.

\section{REZULTATE ȘI DISCUȚII}

Rata prevalenței invaziei cu Dicrocelium lanceolatum, este prezentată în tabelul 2, unde se observă o pondere a ei la examenul coproovoscopic de $71,9 \%$ în cazul ovinelor și 87,7 \% la probele recoltate de la caprine.

Examenul necropsic al ficatului recoltat de la animalele sacrificate, ne demonstrează o pondere generală al dicroceliozei de 94,1\% la probele recoltate de la ovine și $75 \%$ de la cele recoltate de la caprine.

Tabelul 2. Prevalența invaziei cu D. lanceolatum al ovinelor din satul Gradiște, raionul Cimișlia

\begin{tabular}{|c|c|c|c|c|c|c|c|c|c|c|}
\hline \multirow{3}{*}{ Gazda } & \multicolumn{5}{|c|}{ Examenul coproovoscopic } & \multicolumn{5}{|c|}{ Examenul necropsic al ficatului } \\
\hline & \multirow{2}{*}{$\begin{array}{l}\text { Nr. } \\
\text { anim. } \\
\text { examin. }\end{array}$} & \multirow{2}{*}{\begin{tabular}{|l} 
Nr. \\
anim. \\
infest.
\end{tabular}} & \multicolumn{3}{|c|}{$\begin{array}{l}\text { Nr.(\%) animim. cu } \\
\text { ouă }\end{array}$} & \multirow{2}{*}{$\begin{array}{l}\text { Nr. } \\
\text { anim. } \\
\text { examin }\end{array}$} & \multirow{2}{*}{$\begin{array}{l}\text { Nr. } \\
\text { anim. } \\
\text { infest. }\end{array}$} & \multicolumn{3}{|c|}{$\begin{array}{l}\text { Nr.(\%) animim. cu for- } \\
\text { me parazitare }\end{array}$} \\
\hline & & & $<100$ & $<500$ & $<2000$ & & & $<100$ & $<500$ & $<2000$ \\
\hline Ovine & 185 & 133 & 49 & 58 & 26 & 17 & 16 & 4 & 5 & 7 \\
\hline $\begin{array}{l}\% \text { infes- } \\
\text { tare }\end{array}$ & - & 71,9 & 36,9 & 43,6 & 19,5 & & 94,1 & 25,0 & 31,25 & 43,75 \\
\hline Caprine & 65 & 57 & 26 & 18 & 13 & 8 & 6 & 3 & 2 & 1 \\
\hline $\begin{array}{l}\% \text { infes- } \\
\text { tare }\end{array}$ & - & 87,7 & 45,6 & 31,6 & 22,8 & - & 75,0 & 50,0 & 33,3 & 16,7 \\
\hline
\end{tabular}


Numărul de ouă din probele de fecalii examinate, exprimate în ouă pe gram fecalii (EPG), variază de la 50,0 până la 1089,9 la ovine și de la 53,0 până la 1023,2 în cazul caprinelor.

În funcție de cantitatea de ouă depistate, parazitozele sau clasificat în invazii slabe (ușoare), medii (moderate) și grele, conform datelor din tabelul 3.

Tabelul 3. Numărul de ouă de Dicrocelium lanceolatum la examenul coproovoscopic în probele de fecale la ovine și caprine

\begin{tabular}{|c|c|c|c|c|}
\hline \multirow{2}{*}{ Nivelul invaziei } & \multicolumn{2}{|c|}{ Ovine } & \multicolumn{2}{c|}{ Caprine } \\
\cline { 2 - 5 } & $\begin{array}{c}\text { Nr. animale } \\
\text { infestate }\end{array}$ & $\begin{array}{c}\text { EPG (numarul } \\
\text { mediu de ouă) }\end{array}$ & $\begin{array}{c}\text { Nr. animale } \\
\text { infestate }\end{array}$ & $\begin{array}{c}\text { EPG (numarul } \\
\text { mediu de ouă) }\end{array}$ \\
\hline Usoară $(<100<1$ & 49,0 & 50,0 & 26,0 & 53,0 \\
\hline Moderată $<500$ & 58,0 & 248,6 & 18,0 & 232,8 \\
\hline Grea $<2000$ & 26,0 & 1089,9 & 13,0 & 1023,2 \\
\hline \multicolumn{1}{|c|}{ Total: } & $\mathbf{1 3 3 , 0}$ & - & $\mathbf{5 7 , 0}$ & - \\
\hline
\end{tabular}

Ficatul examinat prin inspecție, palpare, secționare la majoritatea aniamalelor infestate prezintă tumefiere, majorare în volum, suprafața boselată, neregulată cu striuri de culoare alba, canalele biliare îngroșate, albicioase-sidefii la culoare, la secționare se observa hipertrofia stromei interlobulare și zone de organ marcate cu ciroză evidentă.

La secționarea canalelor și al vezicii biliare, se depistează un număr mai mare sau mai mic de germeni parazitari (în dependent de caz).

În dependență de numărul de organisme parazitare indentificate, nuvelul invaziei s-a clasificat în: ușoară (<100), moderată (între 100 și 500) sau grea (între 500 și 2000).

La examinarea ficatului, severitatea leziunilor depistate, variază în funcție de nivelul invaziei și de încărcătura cu organisme parazitare. Punctajul mediu al leziunilor (LLS) depistate la ficat stabilit conform cruteriilor din tabelul 1, au fost de 1,5; 3,0 și 4,0 la ovine, ce corespunde infecțiilor ușoare, medii și grele. În cazul caprinelor, LLS au fost de 1,67; 3,0 și 4,0 (tabelul 4). 
Tabelul 4. Ponderea medie de Dicrocoelium lanceolatum la ovine și caprine la examenul hepatic

\begin{tabular}{|l|c|c|c|c|c|c|}
\hline \multirow{2}{*}{ Nivelul invaziei } & \multicolumn{3}{|c|}{ Ovine } & \multicolumn{3}{c|}{ Caprine } \\
\cline { 2 - 7 } & $\begin{array}{c}\text { Nr. animale } \\
\text { infestate }\end{array}$ & $\begin{array}{c}\text { Încărcătura } \\
\text { parazitară }\end{array}$ & $\begin{array}{c}\text { LLS } \\
\text { (media) }\end{array}$ & $\begin{array}{c}\text { Nr. } \\
\text { animale } \\
\text { infestate }\end{array}$ & $\begin{array}{c}\text { Încărcătura } \\
\text { parazitară }\end{array}$ & $\begin{array}{c}\text { LLS } \\
\text { (media) }\end{array}$ \\
\hline Usoară$(<100<1$ & 4,0 & 54,5 & 1,5 & 3,0 & 61,1 & 1,67 \\
\hline Moderată $<500$ & 5,0 & 255,6 & 3,0 & 2,0 & 295,8 & 3,0 \\
\hline Grea $<2000$ & 7,0 & 709,3 & 4,0 & 1,0 & 904,7 & 4,0 \\
\hline Total: & $\mathbf{1 6 , 0}$ & - & - & $\mathbf{6 , 0}$ & - & - \\
\hline
\end{tabular}

Din cele expuse, observăm, că punctajul leziunilor hepatice la ovine și caprine practic este identic, demonstrând un nivel de agresiune egală a organismelor parazitare asupra ficatului la ambele grupe de animale.

Totodată, se observa, că numărul de capre infestate exprimat în \% față de numărul de animale examinate este mai mare față de ovine (tabelul 2), dar numărul de ouă și organisme parazitare practic este la acelaș nivel la ambele categorii de animale (tabelul 3 și 4).

Un alt moment urmarit de noi în studiul nostru, a fost interpretarea nivelului de infestare a ovinelor și caprinelor în dependența de sezon. Astfel, după examinarea figurilor 1 și 2, se observă, că incidența lunară la capre și ovine diferă.

La caprine, cel mai înalt nivel de EPG s-a depistat în lunile ianuarie, februarie, octombrie, iar încărcătură parazitară maximă s-a găsit în lunile septembrie, octombrie, noiembrie și decembrie.

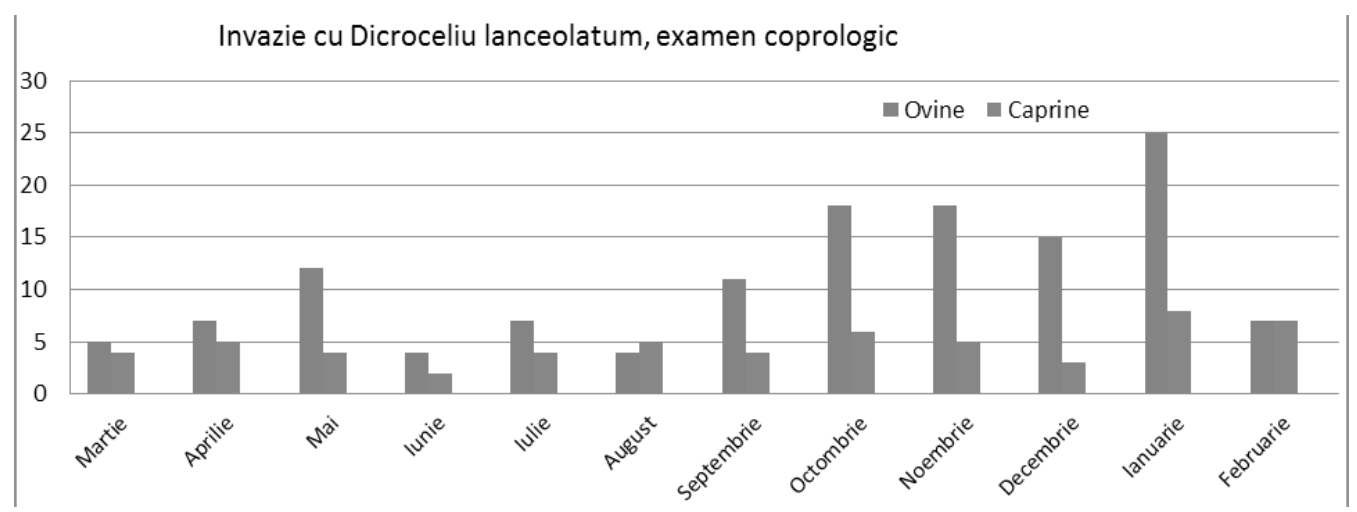

Figura 1. Distribuirea lunară al dicroceliozei conform datelor examenului coprologic 


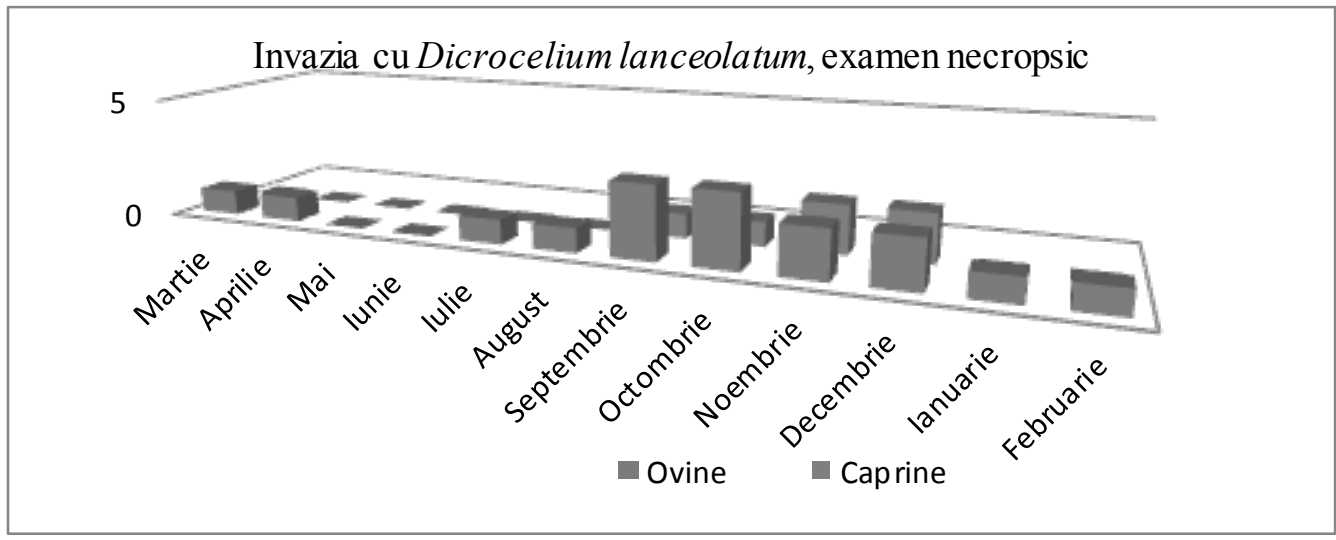

Figura 2. Distribuirea lunară al dicroceliozei conform datelor examenului necropsic al ficatului

La ovine, numărul EPG a atins cote maxime în ianuarie, octombrie, noiembrie și decembrie, iar încărcătura maximală cu organisme parazitare în septembrie, octombrie și decembrie (figura 1 și 2).

Răspândirea sezonieră a dicroceliozei la aceste grupe de animale, reeșind din datele oferite de examenul coproovoscopic al probelor de fecalii și de examenul necropsic al ficatului, ne demonstrează că, invazia parazitară se manifestă mai clar toamna și iarna, în comparație cu sezonul de primăvară și vară (figura 3 și 4).

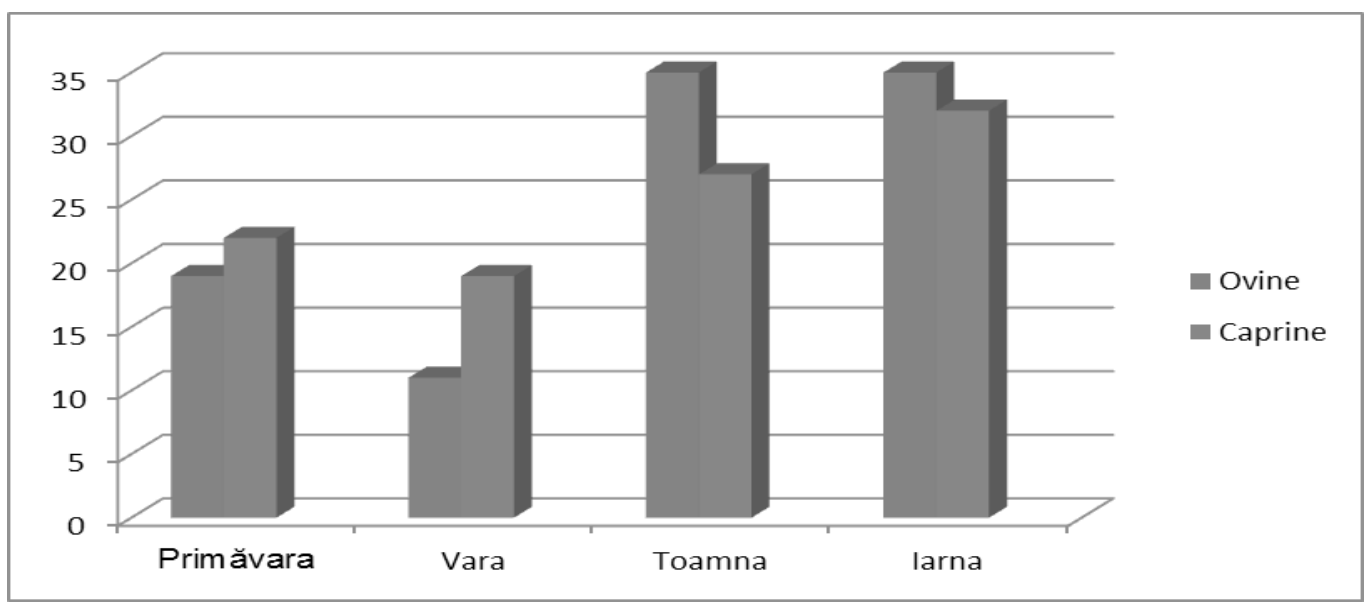

Figura 3. Răspândirea sezonieră a dicroceliozei, evidențiată prin examen coprologic 


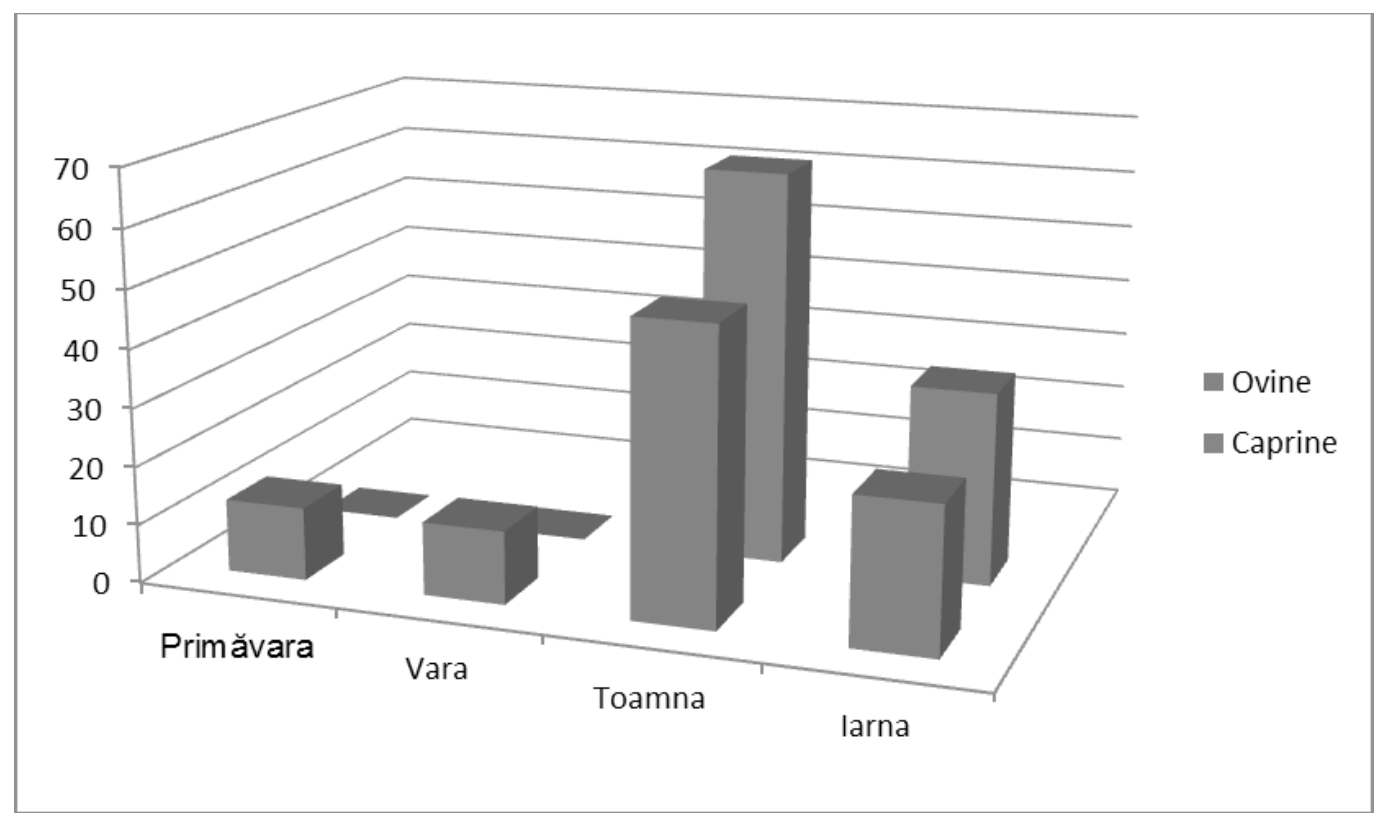

Figura 4. Răspândirea sezonieră a dicroceliozei, evidențiată prin examin necropsic la ficat

La animalele domestice dîn Republica Moldova, dicrocelioza, în principal, se depistează la rumegătoarele mici (ovine și caprine), iar după datele prezentate de unii autori, incidența bolii este ridicată și la bovine $[3,4,5,10]$.

În studiul prezentat, examenul coproovoscopic al probelor de fecalii recoltate de la 185 de ovine și de la 65 de caprine pe parcursul unui an, ne relevă un nivel de infestare de $71,9 \%$ la eșantioanele primire de la ovine și 87,7\% la probele recoltate de la caprine.

Însă, examenul necropsic al ficatului la 17 ovine și 8 caprine, ne demonstrează un nivel de afectare al structurii organului de 94,1\% la ovine și respectiv de 75\% la caprine.

Raportând numărul de ovine depistate ca fiind infestate, la numărul de probe recoltate și cel al probelor de caprine, la numărul de animale bolnave, se observă o prevalență mai ridicată al bolii parazitare în rândul efectivului de ovine. 
Totodată, se conturează faptul, că severitatea modifcărulor morfopatologice la ficat la ovine și caprine sunt practic identice.

Majoritarea ovinelor și caprinelor bolnave, au manifestat o evoluție cronică a bolii, semnele clinice fiind în strânsă corelație cu încărcătura parazitară și gravitatea modificărilor patologice la ficat.

Cercetările noastre au confirmat fluctuația sezonieră lunară și de anotimp a dicroceliozei. Așa, s-a depistat o incidență ridicată al parazitozei în sezonul rece: toamnă și iarnă, comparativ cu primavara și vara, fapt ce poate fi explicat prin contaminarea animalelor în sezonul cald, la pășune cu formele parazitare, care au supravețuit în gazdele intermediare și complementare sau infestarea pășunelor cu ouă de către animalele bolnave, cu reluarea ciclului evolutiv. Apariția semenlor clinice în sezonul rece, este datorată dezvoltării formelor parazitare în organismul gazdei definitive, cu atingerea stadiului de imago și sporirea pontei de ouă.

\section{CONCLUZII}

1. Ferma privată de ovine din satul Gradiște, raionul Cimișlia este nefavorabilă la dicrocelioza ovinelor și caprinelor.

2. Nivelul de infestare al ovinelor este de $71,9 \%$, iar al caprinelor de $87,7 \%$, din totalul probelor cercetate.

3. Există o relație strănsă între cantitatea de ouă depistate în masele fecale, numărul de paraziți localizați în organ și gravitatea modificărilor morfopatologice.

4. Nivelul infestării este direct influențat de condițiile climaterice și starea pășunilor, animalele din zona dată fiind întreținute și pășunate pe locuri și pășuni uscate.

5. Evoluția dicroceliozei este influențată și de anotimp, fapt confirmat și de studiul nostru, având o prevalență mai ridicată toamna și iarna.

\section{BIBLIOGRAFIE}

1. Sanz F., Tarazana J.M., Jurado R. et al. An evaluation of the efficacy of netobimin against Dicrocoelium dendriticum in sheep. Vet. Rec., 1987,120, p. 57-58. 
2. Theodoridis Y., Duncan J.L., MacLean J.M., Himonas C.A. Pathophysiological studies on Dicrocoelium dendriticum infection in sheep. Vet. Parasitol., 1991, 39, p. 61-66.

3. Erhan D., Chihai O., Rusu S. ș.a. Structura poliparazitizmului la bovinele pășunate în ecosisteme de stepă și silvostepă din R. Moldova. În Revista Scientia Parazitologica, Cluj-Napoca, 2005, vol. VI, nr.1-2. P. 31-34.

4. Cercel I. Rusu N. Situaţia epizootologică a helmintozelor la ovine din sectorul particular al raionului Fălești. Chișinău, 2013. În: Lucrări știinţifice, UASM, vol.35, Medicina veterinară. P. 201-204.

5. Nafornița N. Poliparazitizmul la ovine în gospodăriile raioanelor Glodeni și Cimișlia. Chișinău, 2013. În: Lucrări știinţifice, UASM, vol.35, Medicina veterinară. P. 209-211.

6. Naforniţa N. Diversity of parasitosis in sheep in the Republic of Moldova. În: XXV Jubilee International Congress of the Hungarian Association for Buiatrics.Budapest, 2015, p.415.

7. Naforniţa Nicolae. Aspectele invaziei poliparazitare la ovine în zonele geografice ale R. Moldova. În Culegere de lucrări a Simpozionului Știinţific cu participare internaţională dedicat aniversării a 60-a de la fondarea Institutului, IȘPBZMV, Maximovca 2016, p. 222-229.

8. Naforniţa N., Erhan D., Cercel I., Chihai O., Tomșa M.. The particularities of the parasite invasion in sheep in the geographical areas of the Republic of Moldoma. În: Volum de rezumate al Congresului Naţional de Medicină Veterinară, România, Cluj-Napoca, 20-23 septembrie, 2017, p.46.

9. Zgardan E., Tălămbuță N., Cercel I. Contribuţii a studiului poliparazitismului cu endoparaziţi la ovine din R. Moldova. În: Revista Română de Parazitologie, Târgu-Mureș, 2001, vol. XI, nr.1. P. 77-78.

10. Скрябин К. Метод полных гельминтологических вскрытий позвоночных, включая человека. Москва, ИзАательство первого МГУ, 1928. 45 с. 